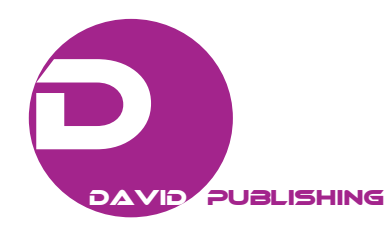

\title{
Application of BIM (Building Information Modeling) and GIS (Geographic Information System) to Railway
}

\section{Maintenance Works in Taiwan}

\author{
Jin-Fang Shr ${ }^{1}$ and Li-Shih $\mathrm{Liu}^{2}$ \\ 1. Department of Construction Management, Chung Hua University, Hsinchu 300, Taiwan, R.O.C. \\ 2. Taiwan Railways Administration, Taichung 400, Taiwan, R.O.C.
}

\begin{abstract}
Based on real jobs, this study was carried out the railway maintenance works in Taiwan. It hopes to use GIS (geographic information system) and BIM (building information modeling) for changing the maintenance model from "post-damage repair" to "preventive maintenance" accordingly, this research will build a railway repairing database that installs all repair data. This database will also connect to GIS so that can be the source of analysis and statistic for repair paln. The main results of research are as follows: (1) all data stored on cloud space that raises the ability to manage and plan on repair; (2) simplify the file work and increase the quantity of case data to the manager who can get more reliable source; (3) the data offer objective judgment to avoid subjective argument. The GIS information can be added to improve the maintenance because of good analysis.
\end{abstract}

Key words: Road maintenance, BIM, GIS, railroad mis-alignment.

\section{Introduction}

In this study, BIM (building information modeling) and GIS (geographic information system) are used to establish such a railway maintenance database. The database contains all information about the current railway routes, including stations, tracks, bridges, tunnels, safety signal equipment, signs and tramline group. The database allows, before actual work starts, the analysis of previous work being done in the same location and an understanding of the earth impact to the maintenance work. Such analysis will be useful for work plans in order to reduce repeated maintenance.

\section{Connotations of BIM (Building} Information Modeling) and GIS (Geographic Information System) Application in Railway Maintenance

The main purpose of this study is to establish

Corresponding author: Jin-Fang Shr, P.E., associate professor, research field: building information modeling. railway maintenance data, combined with the historical data from the GIS system, and the analysis of earth impact so the most favorable maintenance work can be derived. The time duration of a work is also tracked. The study is to be performed as follows:

(1) Establish maintenance database and save them in cloud storage to facilitate data integration;

(2) Combine GIS and the use of IFC (Industry Foundation Classes) data exchange format to allow users retrieve data from the same source;

(3) All TRA (Taiwan Railways Administration) units can access the same database to avoid parochialism or shirk responsibility.

(4) Allow simulations of route overhead and underground projects, as well as route change, route selection to facilitate the coordination of various units.

\section{Study Items}

BIM and GIS application in railway maintenance includes analysis of railway maintenance, inspection management, maintenance operations, security 
monitoring system management, track inspection, maintenance planning and maintenance operations. Also, railway facilities, geography water conservancy hydrological systems, rail interchange buildings and other systems analysis project are included.

\section{Track Inspection and Maintenance Program}

The quality of a work plan directly affects the outcome of the maintenance job; This highlights the importance of planning. The basic considerations of a work plan are as follows:

(1) cost-effective plan to avoid duplication of work;

(2) even distribution of workload within the year;

(3) work uniqueness;

(4) work sequence;

(5) timing of stocking materials, material wear and swap cycles;

(6) sectional office special needs;

(7) worker capability;

(8) maintenance cycle;

(9) holidays, weather, temperature, etc. [1].

\section{BIM (Building Information Modeling)}

The use of BIM system can generate the material requirement information needed in this study. This information is then used to order materials and schedule tasks in order to achieve the following objectives:

(1) Make sure the materials, parts and equipment meet the road maintenance requirements;

(2) Maintain a minimum inventory;

(3) Schedule the maintenance and purchase of materials [2].

In order to achieve these objectives, the material requirement is calculated based on work schedule, material list, inventory and undelivered orders. Recommendations will be made for new orders to replenish the inventory or modify existing orders [3]. With this, timely implementation of road maintenance can be achieved.

\section{GIS (Geographic Information System)}

GIS can be viewed as a computerized map management system. It manages digital information, stores digital maps and displays geographic information. The computer screen is an interface to convey geographic information. The database management focuses on analysis, access and integration of the rich geographical information. Aided by the power of computers, GIS establishes the spatial information for easy access, management, analysis and display. It can also be linked to other data system to provide a wider range of applications [4].

Early geographic information systems focused on the processing of geospatial information and its attribute data with only limited graphic capabilities. With the increasing power of computer, database management, graphical capability, spatial analysis and other technical advances, the function of geographic information system is getting much better. Therefore, this study will use GIS to analyze the railway maintenance database.

\section{Railway Maintenance System Function Analysis}

The information of actual maintenance includes route inspection data (walk inspection and car inspection), Type A inspection, Type B inspection, as well as vibration inspection. Therefore, this study suggests that the main function of a maintenance system should include system function modules, route basic modules and maintenance work modules, as explained in the followings:

(1) Route basic module includes route basic information and its management;

(2) Maintenance work module includes track misalignment data, track maintenance data, track query and analysis.

\section{Database Analysis}

The initial framework of the database is illustrated in Fig. 1. User can modify it as needed. 
9. Case Study of the Establishment and Management of Railway Maintenance Data Query System

Figs. 2-5 show the screenshots of the test case of this study.

\section{Railway Maintenance Data Query System Benefit Analysis}

The benefits achieved from the test case of this study are as follows:

(1) Maintenance-related data are saved and

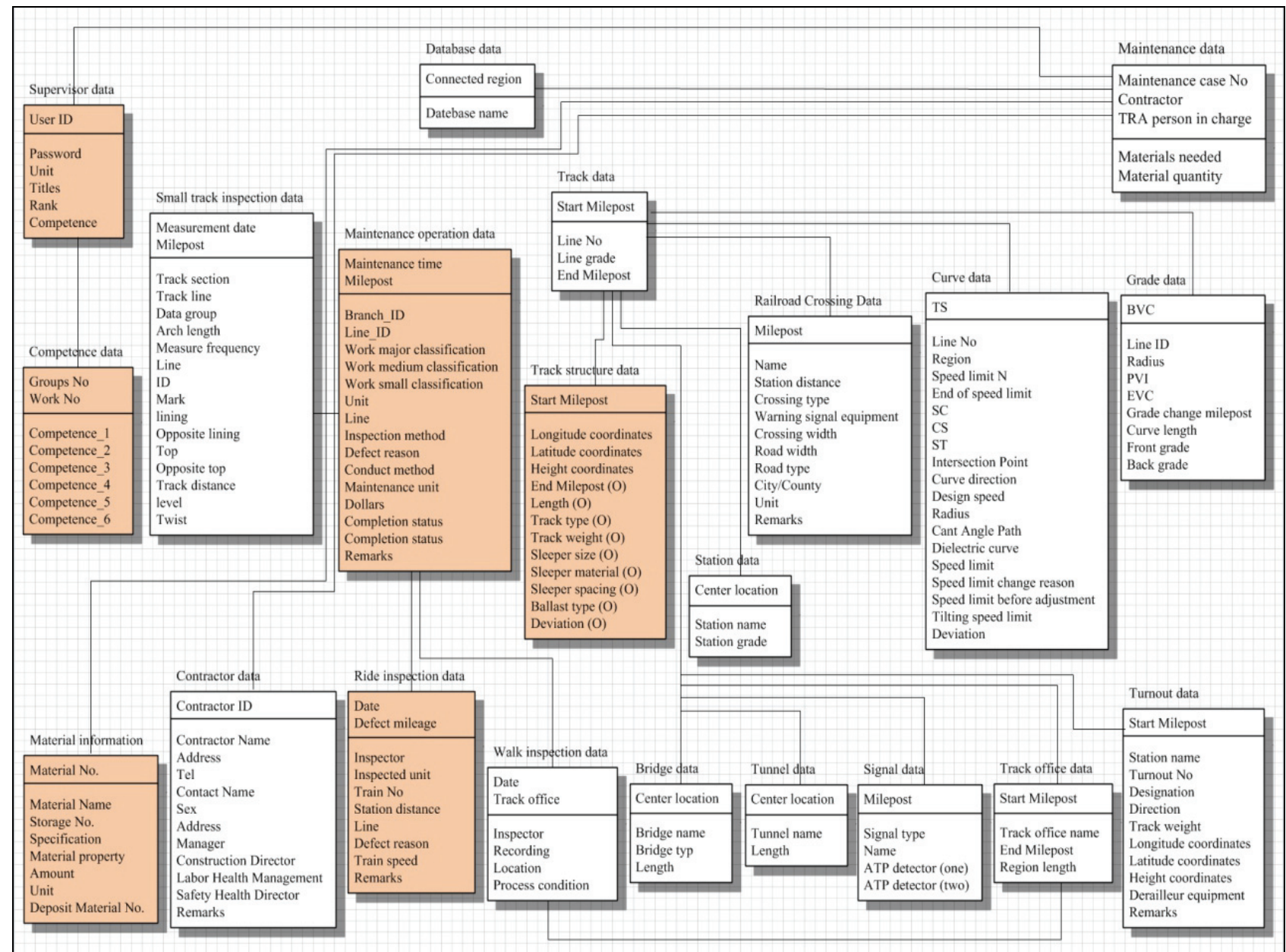

Fig. 1 Database flow chart.

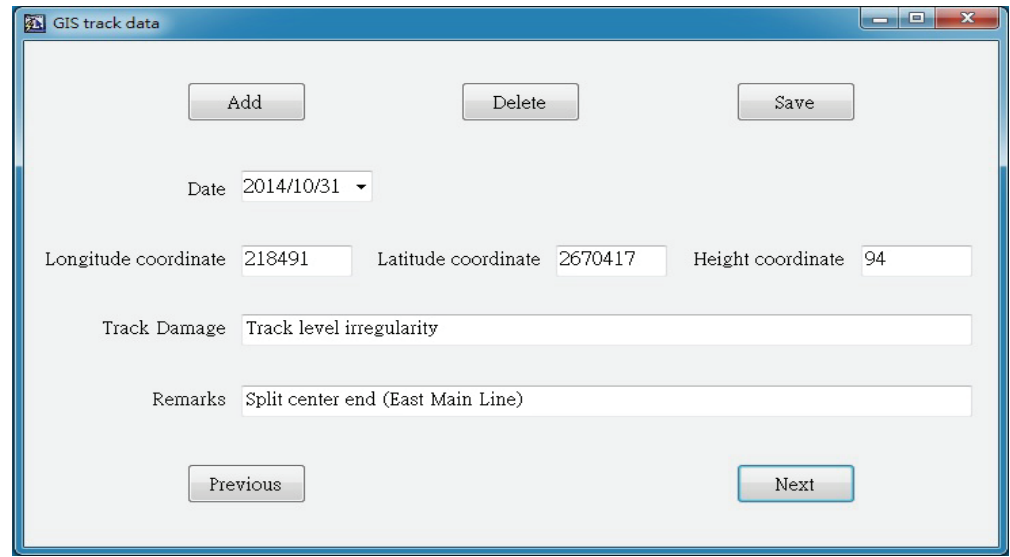

Fig. 2 GIS track data. 
Applying BIM (Building Information Modeling) and GIS (Geographic Information System) to Railway Maintenance Works in Taiwan

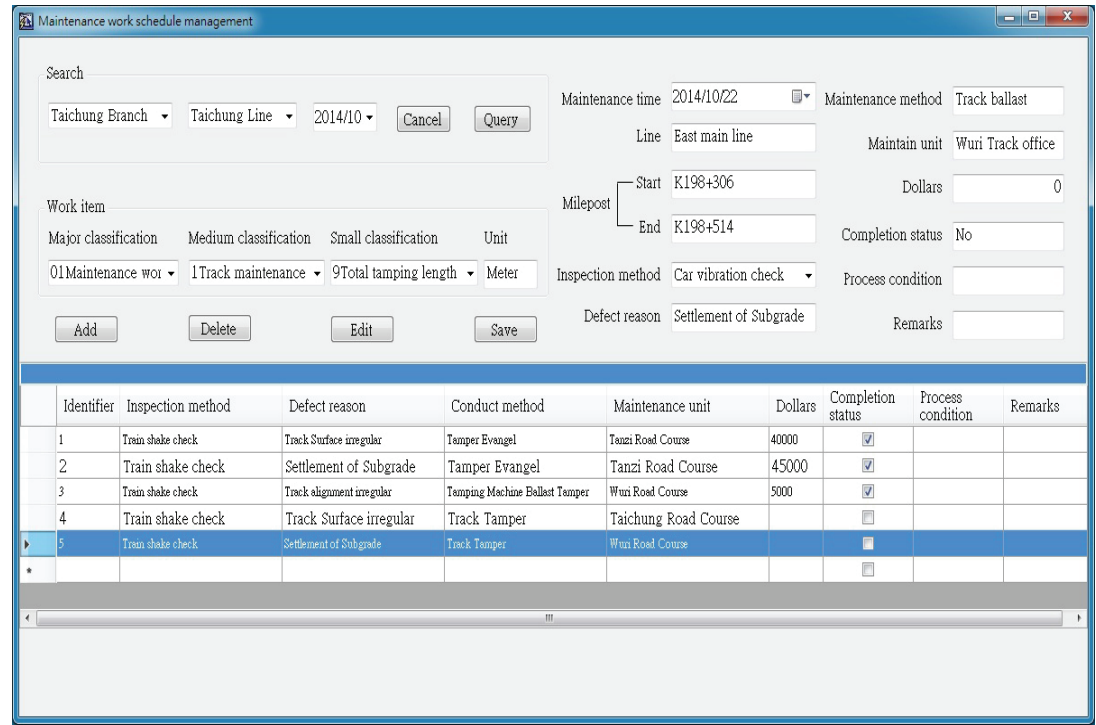

Fig. 3 Maintenance work schedule management.

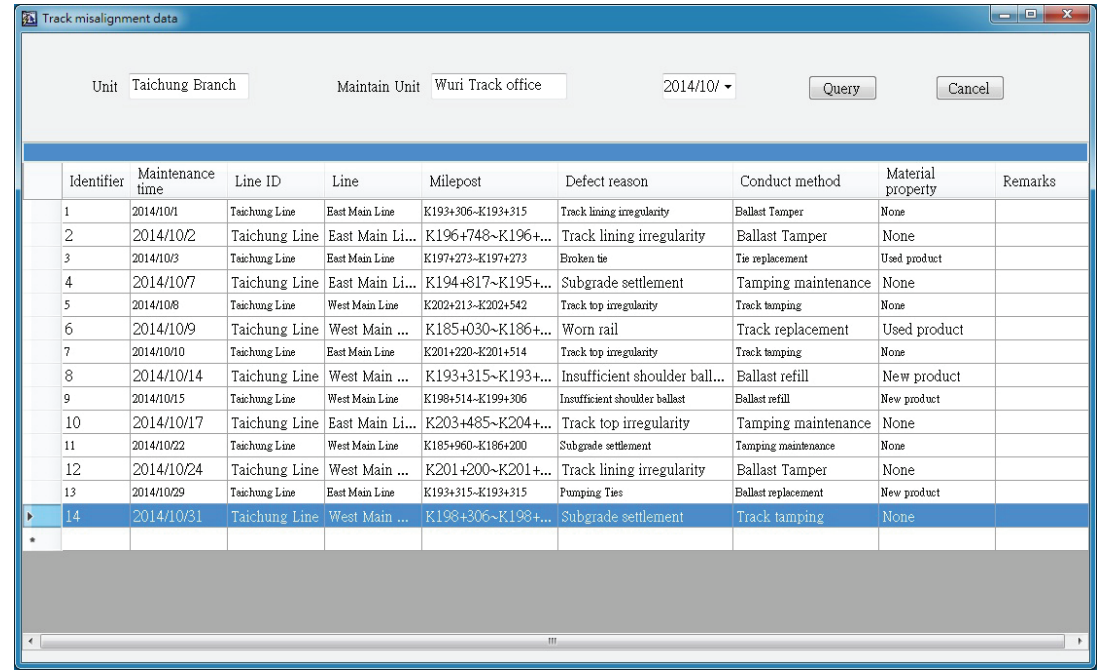

Fig. 4 Track misalignment data.

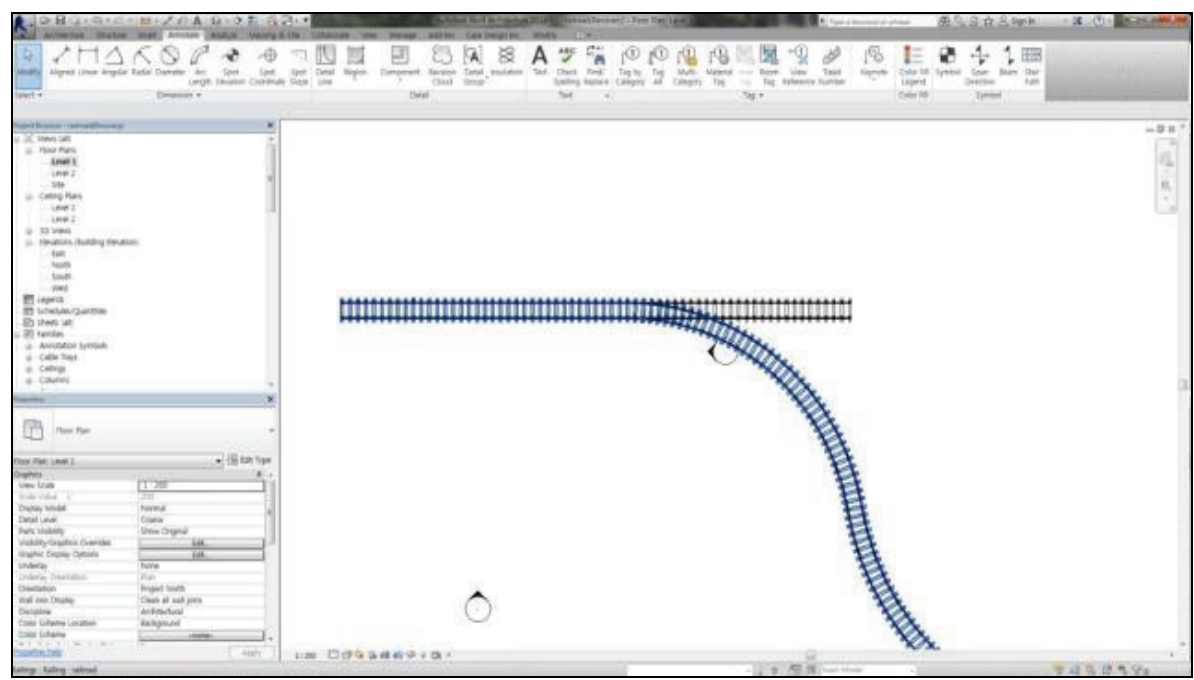

Fig. 5 Route map by Revit. 
managed on cloud storage, preventing accidental loss. The formalization of system database module enables the setting of data attributes and establishes relations between them. Such ability can enhance maintenance management capacity;

(2) All information is saved in the system to facilitate future maintenance scheduling and prepare budgets for emergency repair and annual maintenance. It can also provide early warning for maintenance through statistical analyses;

(3) By matching the maintenance data against GIS geographic information, route sections that need frequent maintenance can be identified. With the saved earth information, optimum maintenance strategies can be derived. The earth information may also be used to find threats for road track, allowing preventive maintenance that reduces risk.

\section{Conclusions}

In this research, the maintenance processes were developed through literature review and expert interviews. With the use of UML (unified modeling language), a maintenance management system has been developed. Through the analysis of the study, the following conclusions can be made:

(1) The system provides track status to managers who can make plans for maintenance and repair. It also avoids dependence on the subjective personal experience for scheduling maintenance;

(2) The system can learn from previous cases. The accumulated experience is a good resource to train new employee and assist the design of new maintenance strategies. Through system parameter settings, one can quickly calculate input data to simplify the system and reduce human error;

(3) In this study, automatic inspection devices and damage survey are used to collect track misalignment data. The track inspection car EM80 automatically checked track status, collecting real-time track misalignment data;

(4) This study utilizes the original data access format to record data. Data of same attributes are recorded in same category. The result is a system that is easy for update and maintenance. Accessed through the database, the data can be easily used for statistical analysis;

(5) Through GIS information, dangerous route sections can be identified. This information can then be used to call for early measures to avoid ballast loss or landslides into routes to prevent possible accidents.

\section{References}

[1] Taiwan Railway Administration, Ministry of Transportation. 2009. Routes Practice Lectures. Lecture, Staff Training Center.

[2] Lin, H. M. 1991. "Dynamics of Bus Materials Inventory Management Systems." Master thesis, National Taiwan University.

[3] Zhang, Y. H. 1980. Transportation Management. Taipei: Huatai Press.

[4] Zhou, T. Y. 2002. The Theory and Practice of Geographic Information Systems. Taipei: Rulin Books. 